\title{
High-dose intravenous vitamin C reduces urinary tract infection post-kidney transplantation
}

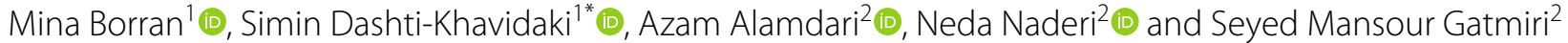

\begin{abstract}
Background: Urinary tract infection (UTI) accounts for about half of all post- kidney transplant infections. There is conflicting data regarding vitamin C and UTI prevention. So far, its efficacy has not been studied in renal transplant patients.

Methods: Kidney transplant candidates were randomized between vitamin $C$ and placebo arms. In the treatment group, patients received vitamin C infusion at a single dose of $70 \mathrm{mg} / \mathrm{kg}$. In another study arm, only the diluent solution was administered. Data regarding bacteriuria during the first hospitalization after transplantation were recorded.

Results: A total of 19 patients were randomized to the placebo $(n=10)$ and vitamin $C(n=9)$ group. The rate of bacteriuria during the first hospitalization after transplantation was significantly lower in the vitamin $C$ group than in the placebo group, $11.1 \%$ versus $60 \%$, respectively. $(P=0.02)$.
\end{abstract}

Conclusion: Vitamin $C$ as a safe treatment is a potential prophylactic agent in post kidney transplantation UTI.

Keywords: Bacteriuria, Kidney transplantation, Urinary tract infection, Vitamin C

\section{Background}

Urinary tract infection (UTI) is the most common infection after kidney transplantation, which is associated with mortality, morbidity, graft rejection, and graft loss [1]. Bacteriuria and cystitis affect more than $25 \%$ of kidney transplant recipients in the first year after transplantation [2]. Given the burden of this infection, finding a solution to prevent it can be conducive. In particular, following the increase in microbial resistance, the effectiveness of antibiotic prophylaxis is reduced. However, non-antibiotic prophylaxis is not affected by this problem. Some non-antibiotic prophylaxis, such as vaginal estrogen in postmenopausal women, probiotics, and vitamin $\mathrm{C}$, has been assessed in studies [3]. The evidence for the effect of vitamin $\mathrm{C}$ in reducing UTI episodes is inconsistent

\footnotetext{
*Correspondence: dashtis@sina.tums.ac.ir

${ }^{1}$ Faculty of Pharmacy, Tehran University of Medical Sciences, P.O.

Box 1417614411, Tehran, Iran

Full list of author information is available at the end of the article
}

[3]. Especially in healthy women, vitamin C has not been effective enough to be recommended as UTI prophylaxis [4]. In contrast, vitamin $C$ intake in pregnant women at a daily dose of $100 \mathrm{mg}$ has been able to prevent bacteriuria and UTI significantly [5].

Given the available evidence, vitamin $C$ may also be useful as a safe supplement in reducing UTI and posttransplant bacteriuria. Accordingly, one of the purposes of this study was to investigate this issue.

\section{Method}

The reported data in this article are one of the secondary outcomes of a clinical trial. Patients who were candidates for the first kidney transplantation from a deceased donor were included after signing written consent form. The study protocol was according to the Helsinki Declaration and approved by the local ethics committee. Patients in the vitamin $\mathrm{C}$ arm received a single-dose parenteral vitamin $\mathrm{C}(500 \mathrm{mg} / 5 \mathrm{ml}$ ampoules, DarouPakhsh Pharmaceutical Company, 
Iran) at a dose of $70 \mathrm{mg} / \mathrm{kg}$ diluted in $0.45 \%$ sodium chloride. The solution was infused within the last hour before transplantation. Patients in the other arm received the same volume of saline solution as a placebo in this period. Supra-physiologic blood concentrations are needed for the effectiveness of vitamin $\mathrm{C}$ to achieve primary outcomes of the trial. The half-life of parenteral vitamin $C$ is short, so vitamin $C$ bolus will attain higher plasma levels for only a short period. Transplant recipients from deceased donors in this study were pre-op admitted only a few hours before transplantation surgery. Often, a dialysis session was also performed during these hours. According to vitamin $\mathrm{C}$ uptake during dialysis, the time interval between the end of the dialysis session and transplant surgery is selected. At this time, it was possible to inject the mentioned dose of parenteral vitamin $\mathrm{C}$ within $1 \mathrm{~h}$. Therefore, the intravenous infusion was selected as the prescribing method during the final hour before surgery. Immunosuppression regimens and prophylaxis of opportunistic infections were similar for the two groups based on the center's protocol. In addition to donors' and recipients' baseline data, allograft function and all information regarding the bacteriuria or crystalluria were also recorded. Data were analyzed using SigmaPlot 12.3 (Systat Software, San Jose, CA). Results are presented as mean \pm SD or median (minimum-maximum) for normal and non-normal distributed quantitative variables and as number (percent) of patients for nominal variables. The $t$ test or Mann-Whitney $U$ test was performed to compare normally and non-normally distributed quantitative variables between the two groups of the study, respectively. Qualitative data were compared using the chi-square or Fisher test. $P<0.05$ was considered statistically significant.

\section{Results}

A total of 19 patients were randomized to the placebo $(n=10)$ and vitamin $C(n=9)$ groups. Demographic characteristics were not statistically different between the two groups (Table 1). The rate of bacteriuria during the first hospitalization after transplantation was significantly lower in the vitamin $\mathrm{C}$ group than in the placebo group $(P=0.02)$. In vitamin $C$ arm, $11.1 \%$ of patients had a positive urine culture versus $60 \%$ in the placebo arm (Table 2). All patients with bacteriuria received antibiotic treatment according to the antibiogram pattern. Following the administration of high-dose intravenous vitamin $\mathrm{C}$, no evidence of oxalate deposition in tissue biopsies nor crystalluria in urine analysis was observed. Ultrasound results showed no kidney stones during the first three months after transplantation.
Table 1 Demographic information of transplant recipients

\begin{tabular}{llll}
\hline Characteristic & $\begin{array}{l}\text { Vitamin C arm } \\
(\boldsymbol{n = 9 )}\end{array}$ & $\begin{array}{l}\text { Placebo arm } \\
(\boldsymbol{n}=\mathbf{1 0})\end{array}$ & $\boldsymbol{P}$ \\
\hline Age (years) & $33.33 \pm 4.59$ & $45.20 \pm 11.03$ & 0.06 \\
Sex (female), $n$ (\%) & $3(33.3)$ & $5(50)$ & 0.65 \\
BMI (Kg/m²) & $22.10(15.5-29.4)$ & $21.65(19.1-25.4)$ & 0.96 \\
Cause of ESKD, $n$ (\%) & & & 0.27 \\
Hypertension & $2(22.2)$ & $1(10.0)$ & \\
Diabetes mellitus & $2(22.2)$ & 0 & \\
Glomerulonephritis & $2(22.2)$ & $2(20.0)$ & \\
PKD & 0 & $2(20.0)$ & \\
Drug-induced & 0 & $2(20.0)$ & \\
Other causes & $3(33.3)$ & $3(30.0)$ & \\
\hline
\end{tabular}

$B M I$ body mass index; ESKD end-stage kidney disease; $P K D$ polycystic kidney disease

\section{Discussion}

Reducing the incidence of bacteriuria with or without symptoms in the vitamin $C$ group was one of the secondary outcomes of a double-blind, randomized, controlled trial. The prevalence of bacteriuria in the vitamin $\mathrm{C}$ group was considerably lower than in the placebo group. Patients in both groups received trimethoprim/ sulfamethoxazole as prophylaxis of Pneumocystis jiroveci pneumonia. It is also useful to some extent in the prevention of urinary tract infections [1]. Also, patients in this center receive ceftriaxone as long as they have a urinary catheter. Despite these common antibiotic treatments, the prevalence of bacteriuria during first hospitalization after kidney transplantation was $60 \%$ in the placebo group.

UTI accounts for about half of all post-kidney transplant infections [6]. The inhibitory impact of vitamin C on the growth of some pathogens like Escherichia coli, Pseudomonas aeruginosa, Klebsiella pneumonia, and Staphylococcus saprophyticus has been shown in some studies $[7,8]$.

The growing rate of antibiotic resistance in urinary tract pathogens has led to the search for non-antibiotic prophylaxis which is not affected by antibiotic resistance [3]. In a study published in 2012 cranberry juice, L-methionine, or both modalities significantly reduced the annual incidence of UTI among kidney transplant recipients with recurrent UTIs compared to the year before the onset of prophylaxis [9]. Information on the administration of a bacterial antigen vaccine for the prevention of UTI is advancing, but this type of treatment has been further studied in non-transplant patients with recurrent UTI $[10,11]$. Since these interventions have not been studied in large population, they are not currently recommended [10]. 
Table 2 Outcomes comparison between study arms

\begin{tabular}{|c|c|c|c|}
\hline Outcome & Vitamin C arm $(n=9)$ & Placebo arm $(n=10)$ & $P$ \\
\hline Bacteriuria during hospitalization, n (\%) & $1(11.1)$ & $6(60.0)$ & 0.02 \\
\hline Concurrent pyuria and bacteriuria, $n(\%)$ & $1(11.1)$ & $5(50)$ & 0.05 \\
\hline Pathogens, $n$ & Escherichia coli (1) & $\begin{array}{l}\text { Escherichia coli (3) } \\
\text { Klebsiella pneumoniae (2) } \\
\text { Enterococcus faecalis (1) }\end{array}$ & \\
\hline Hospitalization duration (days) & $14(9-48)$ & $18(8-32)$ & 0.87 \\
\hline
\end{tabular}

Urinary acidification and production of reactive nitrogen species are proposed mechanisms for the effect of vitamin $C$ on reducing urinary tract infections [4]. Based on in vitro data, nitrite that is produced by bacteria can be reduced to nitric oxide and other nitrogen-reactive intermediates in the presence of vitamin $C$. These nitrogen intermediates have bactericidal effects [8, 12]. Vitamin $C$ can also prevent biofilm formation on the urethral catheter surface. Besides, at the concentration of 80 to $100 \mathrm{mg} / \mathrm{ml}$, vitamin $\mathrm{C}$ exerts an inhibitory effect on a preformed biofilm on the catheters [13]. These desired urinary concentrations can only be achievable by administration of high-dose intravenous vitamin C [14]. On the other hand, in another study, vitamin $C$ could reduce adhesion of uropathogens to the silicone rubber and their colonization in the urine at the dose of $1 \mathrm{~g} /$ day for three consecutive days [15].

Some risk factors make the kidney transplant recipients more susceptible to UTI. These risk factors include female gender, older age, pre-transplant history of UTI, urinary reflux or polycystic kidney disease, long duration of urinary catheterization, and delayed allograft function $[2,9]$. There was no difference regarding these risk factors between patients in the vitamin $C$ and placebo groups in the present study. For further research, designing clinical trials with large sample size by controlling these risk factors between placebo and vitamin $\mathrm{C}$ groups is recommended. It is also suggested to differentiate between asymptomatic bacteriuria and UTI. Besides, recording urine $\mathrm{pH}$ at specified intervals may also be useful in the determination of the mechanism of action of vitamin $C$ on bacteriuria and UTI.

\section{Conclusion}

Vitamin C as a safe supplement may be a potential prophylactic agent against post-kidney transplant UTI. However, the dose and duration of therapy should be optimized in future studies.

\section{Abbreviation}

UTI: urinary tract infection.

\section{Acknowledgements}

This study was a part of Clinical Pharmacy thesis supported by Tehran University of Medical Sciences. Authors sincerely thank the staff of the kidney transplant ward of Imam Khomeini Hospital complex for collaborating with the research team.

\section{Competing interests}

The clinical trial has been encoded IRCT20100111003043N13 in the Iranian registry of clinical trials. Available at: https://en.irct.ir/search/result?query $=$ IRCT20100111003043N13

\section{Authors' contributions}

$\mathrm{MB}$ contributed to research conception and design, data acquisition, data analysis and interpretation, administrative and technical support, manuscript drafting, and critical revision and finalization of the manuscript. SDK contributed to research conception and design, data acquisition, data analysis and interpretation, administrative and technical support, supervision, manuscript drafting, and critical revision and finalization of the manuscript. AA, NN, and SMG contributed to data acquisition, data analysis and interpretation, administrative and technical support, and critical revision and finalization of the manuscript. All authors read and approved the final manuscript.

\section{Funding}

This study was a part of a clinical pharmacy residency thesis from Tehran University of Medical Sciences. There is no funding support.

\section{Availability of data and materials}

The datasets analyzed during the current study are available from the corresponding author on reasonable request.

\section{Ethics approval and consent to participate}

All precipitants signed a written consent form. Also, the study protocol was approved by the local ethics committee of Tehran University of Medical Sciences (IR.TUMS.TIPS.REC.1398.007).

\section{Consent for publication}

Not applicable.

\section{Competing interests}

Authors declare no conflict of interest.

\section{Author details}

${ }^{1}$ Faculty of Pharmacy, Tehran University of Medical Sciences, P.O. Box 1417614411, Tehran, Iran. ${ }^{2}$ Nephrology Research Center, Tehran University of Medical Sciences, Tehran, Iran.

Received: 22 April 2020 Accepted: 24 June 2020

Published online: 28 October 2020

References

1. Green H, Rahamimov R, Gafter U, Leibovitci L, Paul M (2011) Antibiotic prophylaxis for urinary tract infections in renal transplant recipients: a systematic review and meta-analysis. Transpl Infect Dis Off J Transpl Soc 13(5):441-447. https://doi.org/10.1111/j.1399-3062.2011.00644.x 
2. Ariza-Heredia EJ, Beam EN, LesnickTG, Kremers WK, Cosio FG, Razonable RR (2013) Urinary tract infections in kidney transplant recipients: role of gender, urologic abnormalities, and antimicrobial prophylaxis. Ann Transpl 18(1):195-204

3. Beerepoot M, Geerlings S (2016) Non-antibiotic prophylaxis for urinary tract infections. Pathogens 5(2):36. https://doi.org/10.3390/pathogens5 020036

4. Hickling DR, Nitti VW (2013) Management of recurrent urinary tract infections in healthy adult women. Rev Urol 15(2):41

5. Ochoa-Brust GJ, Fernández AR, Villanueva-Ruiz GJ, Velasco R, TrujilloHernández B, Vásquez C (2007) Daily intake of 100 mg ascorbic acid as urinary tract infection prophylactic agent during pregnancy. Acta Obstet Gynecol Scand 86(7):783-787

6. Alangaden GJ, Thyagarajan R, Gruber SA, Morawski K, Garnick J, El-Amm JM et al (2006) Infectious complications after kidney transplantation: current epidemiology and associated risk factors. Clin Transpl 20(4):401-409. https://doi.org/10.1111/j.1399-0012.2006.00519.x

7. Verghese RJ, Mathew SK, David A (2017) Antimicrobial activity of vitamin C demonstrated on uropathogenic Escherichia coli and Klebsiella pneumoniae. J Curr Res Sci Med 3(2):88

8. Carlsson S, Wiklund NP, Engstrand L, Weitzberg E, Lundberg JO (2001) Effects of $\mathrm{pH}$, nitrite, and ascorbic acid on nonenzymatic nitric oxide generation and bacterial growth in urine. Nitric Oxide Biol Chem 5(6):580-586. https://doi.org/10.1006/niox.2001.0371

9. Pagonas N, Hörstrup J, Schmidt D, Benz P, Schindler R, Reinke P et al (eds) (2012) Prophylaxis of recurrent urinary tract infection after renal transplantation by cranberry juice and L-methionine. In: Transplantation proceedings. Elsevier

10. Goldman JD, Julian K (2019) Urinary tract infections in solid organ transplant recipients: guidelines from the American Society of Transplantation Infectious Diseases Community of Practice. Clin Transplant 33(9):e13507

11. Giessing M (2012) Urinary tract infection in renal transplantation. Arab J Urol 10(2):162-168

12. Carlsson S, Weitzberg E, Wiklund P, Lundberg JO (2005) Intravesical nitric oxide delivery for prevention of catheter-associated urinary tract infections. Antimicrobial Agents Chemother 49(6):2352-2355

13. El-Gebaly E, Essam T, Hashem S, El-Baky R (2012) Effect of levofloxacin and vitamin $C$ on bacterial adherence and preformed biofilm on urethral catheter surfaces. J Microb Biochem Technol 4(6):131-136

14. de Grooth H-J, Manubulu-Choo W-P, Zandvliet AS, Spoelstra-de Man AM, Girbes AR, Swart EL et al (2018) Vitamin C pharmacokinetics in critically ill patients: a randomized trial of four IV regimens. Chest 153(6):1368-1377

15. Habash MB, Van der Mei HC, Busscher HJ, Reid G (1999) The effect of water, ascorbic acid, and cranberry derived supplementation on human urine and uropathogen adhesion to silicone rubber. Can J Microbiol 45(8):691-694

\section{Publisher's Note}

Springer Nature remains neutral with regard to jurisdictional claims in published maps and institutional affiliations.

\section{Submit your manuscript to a SpringerOpen ${ }^{\circ}$ journal and benefit from:}

- Convenient online submission

- Rigorous peer review

- Open access: articles freely available online

- High visibility within the field

- Retaining the copyright to your article

Submit your next manuscript at $\mathbf{s p r i n g e r o p e n . c o m ~}$ 